cherish the memory of those days at Cadaqués; his enthusiasm for crustaceans was most stimulating. Our deepest sympathy goes to his widow, Señora Mercedes Colom de Zariquiey, to whom he was devoted, and to his son, his four daughters and their families.

ISABELLA GORDON

\section{Mr. I. Izsak}

ON April 21, 1965, Imre Izsak, chief of satellite research and analysis of the Smithsonian Astrophysical Observatory and lecturer at Harvard University, Cambridge, Massachusetts, died of a heart attack at the age of thirty-six. $\mathrm{He}$ was in Paris attending a COSPAR symposium on trajectories of artificial celestiøl bodies as determined from observations.

In the brief years of his scientific career, he had established himself as a pre-eminent authority on geodesy and had made significant contributions to the study of celestial mechanics. His death is both a deep personal tragedy and an irreparable loss to the scientific community.

Born in the small town of Zalaegerszeg, some two hundred miles from Budapest, Izsak attended the University of Budapest, where he worked in astronomy under the late Karoly Lassovszky (who also later joined the Smithsonian Astrophysical Observatory) and specialized in the investigation of variable stars and galactic clusters. Fleeing Hungary during the 1956 revolution, he began work on solar physies at the Zurich Observatory in November of that year. Two years later he emigrated to the United States and, after a brief period at the Observatory of the University of Cincinnati, joined the staff of the Smithsonian Astrophysical Observatory. On February 24,1964 , he became a citizen of the United States of America. He lived in Cambridge with his wife Emily and an infant son, Andrew.

Izsak pioneered in the development of both theoretical and practical aspects of the application of satellite data to geodesy. He directed the writing of a complex tesseral harmonics programme, which served as a powerful tool in his investigation of geodesy. From it he made determinations of the gravitational potential of the Earth. These results are the best representation so far of the Earth's potential.

Izsak also applied himself to the problem of refining the determinations of the positions of the Observatory's twelve Baker-Nunn camera stations for tracking satellites. In a dynamic approach, he used the Observatory's differential orbit improvement programme to obtain residuals in satellite position, and then analysed these residuals in his own tesseral harmonics programme to determine changes in station co-ordinates and the tesseral harmonics of the geopotential. These latter quantities are strongly correlated, and one cannot solve for one without solving for the other. Shortly before his death, Izsak directed the production of a new computer programme to combine the data from Dr. George Veis's geometric approach with that of his own dynamic approach. This has the effect of reducing the correlation of station positions and the tesseral harmonics. These investigations have shown that the geometric and dynamic methods agree well and have produced the most accurate globel measurements of points on the Earth: the locations of the stations are all now known to within a few tens of motres, and those with tho best determinations to within 10-20 metres. At the beginning of the programme, the corresponding precision was about 100 metres.

As a by-product of these undertakings, Izsak developed techniques for making numerical and analytical calculations using electronic computers. These programmes, which involve problems in celestial mechanics and have significant implications for interplanetary navigation, carry out algebraic operations that would take a life-time to do by hand.
The geodetic work in which Izsak played such a fundamental part will culminate in the publication of the Smithsonian Standard Earth, a concept he and others initiated. That model, which is expected to be the most accurate representation of these features yet available, will incorporate the results of his investigations of the geopotential and of the station co-ordinates.

Izsak wrote a number of scientific papers, including analyses of satellite orbits, a determination of the ellipticity of the Earth's equator, a second-order solution of Vinti's dynamical problem, and various notes on the mechanization of the tedious algebra of celestial mechanics.

Izsak was a warm, charming, witty, gentle person. He gained not only the deep respect but also the spontaneous affection of his colleagues. His association with them was one of mutual inspiration.

\section{Dr. R. F. Farquharson, M.B.E.}

Dr. R. F. Farquharson died suddenly on June 1 at the age of sixty-eight while attending a meeting of the Medical Research Council in Ottawa.

With his death, Canada has lost the pre-eminent figure of its medical profession. To his work as teacher, research worker, consultant and statesman he brought a fine mind and a great heart. That he cared for people was obvious and everyone felt that his wise judgment was always available to them, as indeed it was. He gave the impression that he was prepared to be generous with his unusual talents, and this was coupled with an equally unusual ability to put them to work.

Early in his career it was apparent that he was a man who could accept responsibility, and over the years it was given to him to a degree that will not be seen again. For almost twenty years his advice was called for in connexion with almost every new medical enterprise. Both professional and lay organizations sought his counsel at their inception and some were fortunate enough to be able to continue to count him as one of their officers. Equally deftly he helped other and older groups who were in trouble and who, as they searched for new courses, needed his wisdom and the backing of his moral authority. It was the good fortune of the Royal College of Physicians and Surgeons of Canada to have him as its president in the crucial post-war years 1945-47, when the entire structure of the College was altered so that it could accept its responsibilities to the country for medicine at the specialist and consultant level. He presided at the transformation in 1960 of the Division of Medical Research, National Research Council, into the virtually autonomous Medical Research Council. During the Second World War he was consultant in medicine to the Director of Medical Services of the Royal Canadian Air Force. Immediately after the War he worked in association with the Director-General of Treatment Services, Department of Veterans' Affairs, and had much to do with the high standard of patient care which was evolved in association with the medical schools. From 1949 until 1952 he was a member of the Defence Research Board. During the discharge of these and innumerable other duties he was held in high esteem as a teacher. $\mathrm{He}_{e}$ was a brilliant consulting physician who remained to the end quietly and privately surprised that others did not havo the skill at the bedside which was his.

It was natural that many honours should come his way. These he carried as lightly and with as little sense of self-importance as he carried the many secrets which were shared with him. In 1946 he was made a member of the Order of the British Empire, and in 1949 came the first of eight honorary degrees. He was elected a Fellow of the Royal Society of Canada in 1960. The clinical investigation unit in his own hospital has carried his name 